\title{
A MUTATION FROM BLACK TO BROWN IN MUS MUSCULUS
}

\author{
MARGARET E. WALLACE \\ Department of Genetics, University of Cambridge
}

Received II.xii.49

A BUCK, 12/76.188 i, which was bred from an intercross for brown and misty in coupling $(m b / \mathrm{MB} \times m b / \mathrm{MB})$, and was itself phenotypically a non-misty black, was crossed, for purposes other than the present subject, to a misty-brown doe (mating $12 / 82$ ) and a non-misty brown doe (mating E/296). By the former doe he has thrown twelve nonmisty blacks to date, and by the latter one brown and twenty-four blacks.

$\chi^{2}$ on $\mathrm{I}: \mathrm{I}$ of the $\mathrm{B}: b$ segregation of all the buck's progeny is $33^{\cdot} \cdot \mathrm{T} 8 \mathrm{I}$ for one degree of freedom.

The simplest explanation for this performance is that the buck is homozygous for non-misty and black, and that the one brown offspring recorded is the result of a mutation of black to brown affecting one of his sperm.

Unfortunately the brown was produced amongst the first eleven of his offspring. As there was a two-thirds chance of the buck being heterozygous, the brown was not unexpected and was killed when fully classified, that is at the age of eighteen days when $\mathrm{B} / b$ was also classified. There is thus no possibility of testing the mutant gene. 